\title{
Evaluation of neurofilament light chain in the cerebrospinal fluid and blood as a biomarker for neuronal damage in experimental pneumococcal meningitis
}

Ngoc Dung Le ${ }^{1,2}$, Lukas Muri ${ }^{1}$, Denis Grandgirard ${ }^{1}$, Jens Kuhle ${ }^{3}$, David Leppert ${ }^{3}$ and Stephen L. Leib ${ }^{1 *}$ (D)

\begin{abstract}
Background: Pneumococcal meningitis (PM) remains a global public health concern and affects all age groups. If acquired during infancy or childhood, permanent neurofunctional deficits including cognitive impairment, cerebral palsy, and secondary epilepsy are typical sequelae of neuronal injury. Determination of patients at risk for the development of brain injury and subsequent neurofunctional sequelae could help to identify patients for focused management. Neurofilament light chain (NfL) is an axonal cytoskeletal protein released upon neuronal injury into the cerebrospinal fluid (CSF) and blood. As little is known about the course of neurofilament release in the course of PM, we measured CSF and serum NfL levels longitudinally in experimental PM (ePM).
\end{abstract}

Methods: Eleven-day-old infant Wistar rats were infected intracisternally with Streptococcus pneumoniae and treated with ceftriaxone. At 18 and $42 \mathrm{~h}$ post-infection (hpi), the blood and CSF were sampled for NfL measurements by a single molecule array technology. Inflammatory cytokines and MMP-9 in CSF were quantified by magnetic bead multiplex assay (Luminex ${ }^{\circledast}$ ) and by gel zymography, respectively.

Results: In ePM, CSF and serum NfL levels started to increase at 18 hpi and were 26- and 3.5-fold increased, respectively, compared to mock-infected animals at $42 \mathrm{hpi}(p<0.0001)$. CSF and serum NfL correlated at $18 \mathrm{hpi}(p$ $<0.05, r=0.4716)$ and $42 \mathrm{hpi}(p<0.0001, r=0.8179)$. Both CSF and serum NfL at 42 hpi strongly correlated with CSF levels of IL-1 $\beta$, TNF- $a$, and IL- 6 and of MMP-9 depending on their individual kinetics.

Conclusion: Current results demonstrate that during the peak inflammatory phase of ePM, NfL levels in CSF and serum are the highest among CNS disease models studied so far. Given the strong correlation of CSF versus serum $\mathrm{NfL}$, and its CNS-specific signal character, longitudinal measurements to monitor the course of PM could be performed based on blood sample tests, i.e., without the need of repetitive spinal taps. We conclude that NfL in the serum should be evaluated as a biomarker in PM.

Keywords: Pneumococcal meningitis, Neuroinflammation, Neuronal damage, Neurofilament light chain, Serum biomarker

\footnotetext{
* Correspondence: stephen.leib@ifik.unibe.ch

${ }^{1}$ Neuroinfection Laboratory, Institute for Infectious Diseases, University of Bern, Friedbühlstrasse 51, 3001 Bern, Switzerland

Full list of author information is available at the end of the article
}

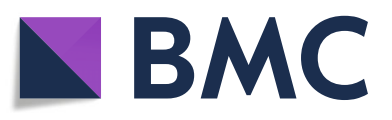

( The Author(s). 2020 Open Access This article is licensed under a Creative Commons Attribution 4.0 International License, which permits use, sharing, adaptation, distribution and reproduction in any medium or format, as long as you give appropriate credit to the original author(s) and the source, provide a link to the Creative Commons licence, and indicate if changes were made. The images or other third party material in this article are included in the article's Creative Commons licence, unless indicated otherwise in a credit line to the material. If material is not included in the article's Creative Commons licence and your intended use is not permitted by statutory regulation or exceeds the permitted use, you will need to obtain permission directly from the copyright holder. To view a copy of this licence, visit http://creativecommons.org/licenses/by/4.0/ The Creative Commons Public Domain Dedication waiver (http://creativecommons.org/publicdomain/zero/1.0/) applies to the data made available in this article, unless otherwise stated in a credit line to the data. 


\section{Background}

Streptococcus pneumoniae and Neisseria meningitidis are the most prevalent causative pathogens for childhood bacterial meningitis (BM) [1] with fatality rates up to $50 \%$ in resource-poor settings [2]. Pneumococcal meningitis (PM) acquired during infancy or childhood is associated with a high risk for neurofunctional deficits which profoundly affect the quality of life. One-third of PM survivors display long-lasting neurological sequelae including hearing loss, cerebral palsy, secondary epilepsy, and cognitive impairment $[3,4]$.

In reaction to the bacterial infection, the host's immune response causes an excessive inflammation that leads to injury to the central nervous system (CNS) $[4,5]$. The brain structural damage induced in the course of PM results also from vasospasms and reduced blood flow that eventually cause cortical necrosis [6] and apoptotic cell death in the hippocampal subgranular zone of the dentate gyrus [7-9]. Additionally, brain-diffuse ischemic axonal injury and Wallerian degeneration have been demonstrated in brain autopsy of human BM and in experimental PM (ePM) [10]. Along with inflammatory signaling molecules like IL-1 $\beta$, TNF- $\alpha$, and IL-6, effector molecules such as matrix metalloproteinases (MMPs) are released in high amounts into the cerebrospinal fluid (CSF) [11], promoting blood-brain barrier (BBB) opening and neutrophil recruitment $[12,13]$ and may exert as well direct toxicity on neurons $[14,15]$. While their levels are linked to the likelihood for long-term sequelae [11, 14], their relevance as biomarkers in clinical practice is limited, as they reflect disease activity only in CSF, but not in the serum. Hence, longitudinal spinal taps would be required to use them for disease monitoring. Functionally, they relate to neuronal damage only indirectly and no biofluid marker has been established in BM that measures neuronal damage itself.

Neurofilaments (NFs) are a major component of the axonal cytoskeleton and consist of three subunits: NF light chain (NfL), medium chain, and heavy chain. Upon axonal damage, NFs are released into the extracellular space and eventually into the CSF and blood. Their increased levels can be used as a biomarker of neuronal damage [16], indicative of actual disease activity and predicting later disease course in neurodegenerative diseases (multiple sclerosis [17], Alzheimer's and Parkinson's disease [18], Huntington disease [19], and amyotrophic lateral sclerosis (ALS) [20]), traumatic brain injury [21], and viral and autoimmune encephalitis [22].

With the advent of the single-molecule array (Simoa) technology, the sensitivity for quantitation of NfL has been increased to a degree that levels in serum or plasma can be accurately quantified [23]. This technical progress, the specificity of the signal as of exclusive neuronal origin and the strong correlation between CSF and serum NfL demonstrated in numerous studies, made it possible to use a serum instead of CSF-based analysis. Thus, longitudinal assessment as an inherent prerequisite to specifically monitor CNS disease activity and drug response can be implemented based on blood tests whose acquisition is far less invasive than repetitive lumbar puncture [24].

Only one study has evaluated NFs as a biomarker for neuronal injury in BM across an array of infectious agents. CSF concentrations of NF heavy chain were increased by $85 \%(22 / 26)$ children with BM; peak levels in patients with neurological sequelae were significantly higher than in those without [25].

Present results are the first to investigate the course of NfL in ePM. We hypothesized that serum NfL is a useful biomarker to monitor disease activity in $\mathrm{BM}$, as its kinetics accurately correlated with those in CSF, as well as with typical inflammatory mediators upregulated in ePM.

\section{Methods}

\section{Infecting organism}

A clinical isolate of Streptococcus pneumoniae (serotype 3) was cultured overnight in brain heart infusion (BHI) medium, diluted tenfold in fresh, prewarmed BHI medium, and grown for $5 \mathrm{~h}$ to reach the logarithmic phase. The bacteria were centrifuged for $10 \mathrm{~min}$ at $3100 \times$ $g$ at $4{ }^{\circ} \mathrm{C}$, washed twice, and resuspended in saline $(\mathrm{NaCl}$ $0.85 \%)$. The resuspended bacterial solution was then further diluted in saline to the desired optical density $\left(\mathrm{OD}_{570 \mathrm{~nm}}\right)$. The inoculum concentration was determined by serial dilution and culturing on Columbia sheep blood agar (CSBA) plates.

\section{Infant rat model of ePM}

All animal studies were approved by the Animal Care and Experimentation Committee of the Canton of Bern, Switzerland (license no. BE 01/18). A well-established infant rat model of PM was used [26, 27]. Eleven-day-old male and female Wistar rat pups together with their dams were purchased from Charles Rivers (Sulzfeld, Germany). The dams were provided with tap water and pellet diet ad libitum. Animals were kept in a room at controlled temperature $\left(22 \pm 2{ }^{\circ} \mathrm{C}\right)$ and natural light. Intracisternal injections were performed on pups by injection of $10 \mu \mathrm{l}$ of the inoculum containing $5.25 \pm 3.4 \times 10^{5} \mathrm{CFU} / \mathrm{ml}$ of living S. pneumoniae serotype 3 . Control animals received an equivalent volume of saline. PM was confirmed by the quantitative analysis of bacterial titers in the cerebrospinal fluid (CSF) at $18 \mathrm{hpi}$. Five microliters of CSF was gained by puncture of the cisterna magna, followed by serial dilution and cultivation on CSBA plates. To confirm PM in animals which were not punctured at $18 \mathrm{hpi}$, the blood was cultivated on CSBA plates. The numbers of animals per independent experiments was determined by a maximum litter size of 14 pups. Given the probability of premature abortion of experiments due to reaching humane 
endpoints or spontaneous death in infected animals, or unsuccessful infection, experiments were designed with 4 mock-infected and 10 infected animals per experiment. Four independent experiments were performed, for a total of 56 animals. Animals without confirmed PM were excluded $(n=9)$. All animals received ceftriaxone (100 $\mathrm{mg} / \mathrm{kg}$, i.p., twice daily [b.i.d.]) at 18 and 24 hpi. With the dosing regimen applied in the present study, therapeutic concentrations are maintained until the end of the experiment, so there is no resurgence of bacterial infection at later time points. Animals were weighed and clinically scored according to the following scoring scheme $(1=$ coma, 2 = does not turn upright, 3 = turns upright in $>5 \mathrm{~s}$, 4 = turns upright in $<5 \mathrm{~s}, 5=$ normal) at $0,18,24$, and before sacrificing at $42 \mathrm{hpi}$. Spontaneous mortality was documented. Blood sampling in all animals was performed at 18 hpi by puncturing the facial vein using a 20-gauge needle. Blood ( $<10 \%$ of total blood volume) was collected in Microvette $^{\odot} 200 \mathrm{Z}$ (clotting activator/serum) (Sarstedt), kept at room temperature for at least $30 \mathrm{~min}$, and then centrifuged for $10 \mathrm{~min}$ at $13,000 \times g$ at $4{ }^{\circ} \mathrm{C}$. The supernatant (serum) was collected and kept at $-80^{\circ} \mathrm{C}$ for later analysis. Following blood sampling, CSF samples of half of the animals $(n=28)$ were obtained by puncture of the cisterna magna using a 30-gauge needle. CSF samples were only collected from half of the animals to assess if this additional puncture causes an artefactual increase in NfL level. CSF samples were then centrifuged for $10 \mathrm{~min}$ at $13,000 \times g$ at $4{ }^{\circ} \mathrm{C}$, and supernatants were stored at $80{ }^{\circ} \mathrm{C}$ for later use. Animals were treated with ceftriaxone after the collection of specimens. At $42 \mathrm{hpi}$, the blood and then CSF were sampled again from all animals, followed by sacrificing with pentobarbital (Esconarkon ${ }^{\circledR}, 150 \mathrm{mg} / \mathrm{kg}$, i.p., Streuli Pharma AG, Switzerland). Of note, throughout the experiment, each animal was only punctured once to avoid a possible artificial increase of NfL in CSF and serum by multiple puncturing. Accordingly, if an animal was not punctured successfully or died spontaneously, no CSF could be collected which then resulted in lower datapoints.

\section{Analysis of cytokine levels in CSF}

Cytokines known to be upregulated in PM (IL-1 $\beta$, TNF$\alpha$, IL-6) were assessed using a magnetic multiplex assay (Rat Magnetic Luminex ${ }^{\bullet}$ Assay, Rat Premixed MultiAnalyte Kit, R\&D Systems, Bio-Techne) on a Bio-Plex 200 station (Bio-Rad Laboratories) as earlier reported [27]. Five microliters of CSF collected at 18 and $42 \mathrm{hpi}$ were diluted to a final volume of $50 \mu \mathrm{l}$. For each sample, a minimum of 50 beads was measured. For samples below the detection limit, a value corresponding to the detection limit provided by the manufacturer was used and multiplied by the dilution factor (IL-1 $\beta 2.93 \mathrm{pg} / \mathrm{ml}$; TNF- $\alpha 11.5$ pg/ml; IL-6 23.2 pg/ml).

\section{Analysis of NfL levels in CSF and serum}

$\mathrm{NfL}$ in CSF and serum were analyzed using a SIMOA ${ }^{\circ}$ immunoassay (Quanterix Corporation, Billerica, MA, USA) as previously described [17]; the antibody pair of this assay is full cross-reactive with murine NfL.

\section{Analysis of MMP-9 levels in CSF}

The amount of MMP-9 in CSF was assessed by gel zymography as reported earlier [11]. Briefly, CSF samples $(2 \mu \mathrm{l})$ were diluted with $5 \mu \mathrm{l}$ of $4 \times$ sample buffer $(0.5 \mathrm{M}$ Tris$\mathrm{HCl}$ pH 6.8, 10\% sodium dodecyl sulfate (SDS) $20 \%$, $42.5 \%$ glycerol, $0.5 \%$ bromophenol blue) and $13 \mu \mathrm{l}$ of distilled water $\left(\mathrm{dH}_{2} \mathrm{O}\right)$ to a loading volume of $20 \mu \mathrm{l}$ and electrophoresed under non-reducing conditions in 10\% SDSpolyacrylamide gels containing type A gelatin from porcine skin (1\%; Sigma, Buchs, Switzerland) as proteinase substrate. After electrophoresis for $2 \mathrm{~h}$ at $100 \mathrm{~V}$, gels were incubated for $2 \times 30 \mathrm{~min}$ in SDS-removing buffer (1\% Triton $\mathrm{X}-100$ ), washed $5 \times$ with $\mathrm{dH}_{2} \mathrm{O}$, followed by incubating in incubation buffer $(1.5 \mathrm{M} \mathrm{NaCl}, 0.5 \mathrm{M}$ Tris- $\mathrm{HCl} \mathrm{pH} 7.6$, $4 \% \mathrm{NaN}_{3}, 10 \mathrm{mM} \mathrm{CaCl}$ ) for $18 \mathrm{~h}$ at $37^{\circ} \mathrm{C}$ on a shaker. Gels were then stained with Coomassie blue $(0.05 \%$ Coomassie blue in 40\% methanol, $10 \%$ glacial acid, 50\% $\left.\mathrm{dH}_{2} \mathrm{O}\right)$ to visualize the substrate lysis zones of MMP-9 $(92 \mathrm{kDa})$ and MMP-2 $(72 \mathrm{kDa})$. The gelatinolytic activities of MMP-9 and MMP-2 were analyzed using ImageJ software. The amount of expressed MMP-9 was determined as a percentage of that of the constitutively expressed MMP-2 for each sample [26].

\section{Statistical analysis}

Statistical analyses were performed with GraphPad Prism (Prism 7; GraphPad Software Inc., San Diego, USA). Data were first tested for normal distribution with the Kolmogorov-Smirnov test.

To compare the differences between the non-normally distributed data, a non-parametric Mann-Whitney test was used. Correlations were assessed by using the Spearman correlation coefficient. The results are presented as median with interquartile range. A $p$ value of 0.05 was considered as statistically significant, with ${ }^{*} p<0.05,{ }^{* *} p$ $<0.01,{ }^{* * * *} p<0.001$, and ${ }^{* * * * *} p<0.0001$.

\section{Results}

Intracisternal puncture causes a minor increase in CSF NfL levels

In the present ePM model, intracisternal punctures are performed to inoculate $S$. pneumoniae or saline in a first step and to collect CSF samples later. To determine whether this mechanical trauma leads to an artifactual neuronal damage, we measured serum NfL levels of animals before any intervention and compared them with animals at 18 hpi which have been inoculated with saline at baseline. 
Baseline levels of serum NfL of animals before any intervention (mean $\pm \mathrm{SD} ; 299.1 \pm 26.4 \mathrm{pg} / \mathrm{ml}$ ) were not different from those of mock-infected animals at $18 \mathrm{hpi}(293.7$ $\pm 168.3 \mathrm{pg} / \mathrm{ml})(p=0.18)$ (Fig. 1a), indicating that the first intracisternal puncture for the inoculation of S. pneumoniae or saline had no impact on serum levels. In mockinfected animals undergoing a second intracisternal puncture at 18 hpi for CSF collection, serum levels (471.4 \pm $318.6 \mathrm{pg} / \mathrm{ml}$ ) at $42 \mathrm{hpi}$ increased 1.6-fold compared to those having been punctured only at baseline (299.3 \pm $137.2 \mathrm{pg} / \mathrm{ml})(p=0.33)$. Accordingly, CSF levels of NfL showed a 1.8-fold increase in animals having had a second intracisternal puncture $(789 \pm 303.9 \mathrm{pg} / \mathrm{ml})$ compared to those without $(436.7 \pm 163.2 \mathrm{pg} / \mathrm{ml})(p=0.01)$ (Fig. 1b). In contrast, at 42 hpi CSF and serum NfL levels in infected animals were more than $2000 \%(15,319.6 \pm 36,745.4 \mathrm{pg} /$ $\mathrm{ml})$ and $300 \%(1307.5 \pm 1062.6 \mathrm{pg} / \mathrm{ml})$ increased, respectively (pooled analysis of $18 \mathrm{hpi}$ punctured and nonpunctured) (Fig. 1c), compared to levels in mock-infected animals (Fig. 1b). We conclude that the second intracisternal puncture at $18 \mathrm{hpi}$ did cause a microtrauma, possibly contributing to $a<2 \%$ increase of NfL levels in CSF of the total amount observed in the course of ePM, while serum levels in infected animals were not impacted by a second intracisternal puncture. We therefore have pooled the two groups (with and without second intracisternal puncture) for further analyses.

\section{Animals with ePM have increased CSF and serum NfL concentrations}

In the next experiment, we evaluated the time course of NfL increase in infected animals. At $18 \mathrm{hpi}$, CSF NfL concentrations $(2517.1 \pm 3336.3 \mathrm{pg} / \mathrm{ml})$ trended to be higher compared to mock-infected animals $(590.1 \pm 186.9 \mathrm{pg} / \mathrm{ml})$ $(p=0.06)$ and at $42 \mathrm{hpi}$, they showed a 26-fold higher level $(15,319.6 \pm 36,745.4 \mathrm{pg} / \mathrm{ml})$ compared to mock-infected controls $(590.1 \pm 296.4 \mathrm{pg} / \mathrm{ml})(p<0.0001)$ (Fig. $2 \mathrm{a})$. At the same time point, serum NfL levels of infected animals $(1362.8 \pm 1136 \mathrm{pg} / \mathrm{ml})$ were 3.5 -fold higher than mockinfected animals $(385.4 \pm 253.1 \mathrm{pg} / \mathrm{ml})(p<0.0001)$, while at $18 \mathrm{hpi}$ the levels between the two groups were similar (Fig. 2b). The relative increase of NfL levels over time in infected animals was highly significant in both CSF $(p<$ $0.01)$ and in serum $(p<0.0001)$, whereas those of mockinfected animals remained stable in both fluid compartments (Fig. 2a, b).

At 18 hpi NfL levels in CSF and serum were correlated $(p<0.05, r=0.4716)$ with an average CSF concentration $(1908.6 \pm 2877 \mathrm{pg} / \mathrm{ml})$ being 6.9 -fold higher than that in serum $(276.9 \pm 144.8 \mathrm{pg} / \mathrm{ml}$ ) (Fig. 2c). A stronger correlation was also observed at $42 \mathrm{hpi}(p<0.0001, r=0.8179)$ with average CSF levels $(9848.6 \pm 29768 \mathrm{pg} / \mathrm{ml})$ being 9.8fold higher than in serum $(1007.3 \pm 1029 \mathrm{pg} / \mathrm{ml})$ (Fig. $2 \mathrm{~d})$.

\section{Kinetics of cytokines and MMP-9 upregulation in the course of ePM}

We measured the dynamic change of inflammatory cytokines TNF- $\alpha$, IL- 6 , and IL- $1 \beta$ and of MMP-9 during the acute phase of ePM and correlated values with those of NfL. The concentrations of all cytokines were upregulated in infected animals at $18 \mathrm{hpi}$ compared to mock-infected animals (Fig. $3 \mathrm{a}-\mathrm{c}$ ) but decreased at $42 \mathrm{hpi}$ to similar levels as in mock-infected ones for TNF- $\alpha$ and IL-6; only IL-1 $\beta$ remained higher in infected versus mock-infected animals $(p=0.02)$ (Fig. 3c). The relative amount of MMP9 (MMP-9/MMP-2 index) followed a similar kinetic with increased levels in infected compared to mock-infected

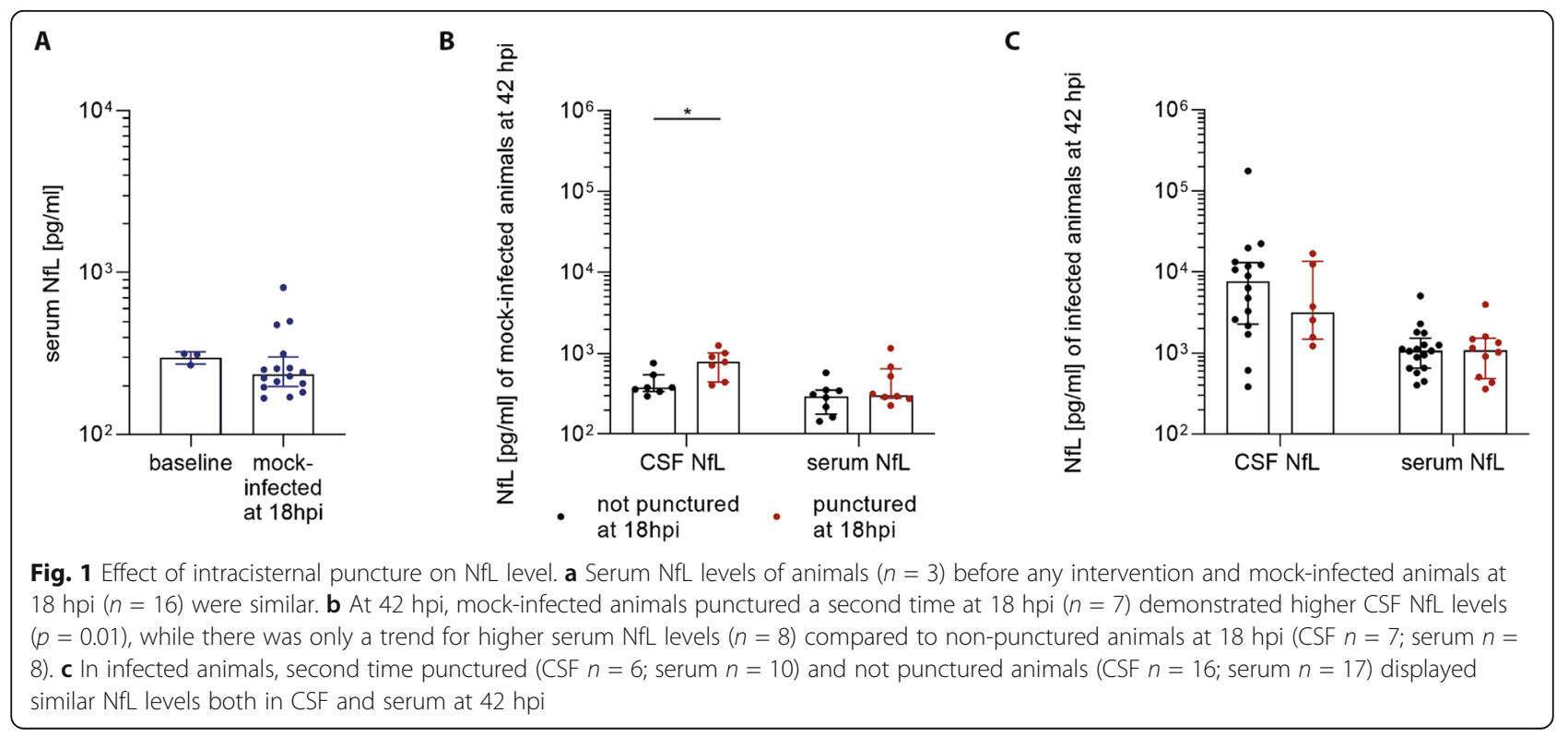


A

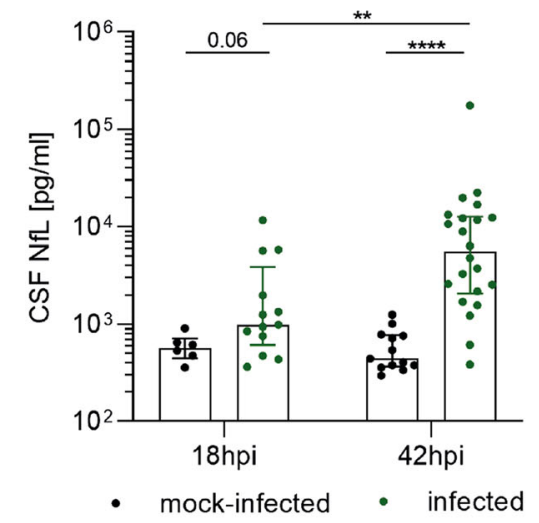

C

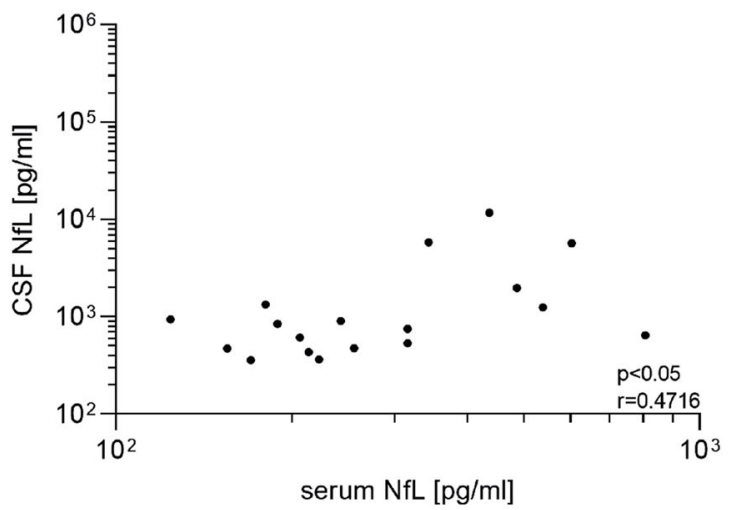

B

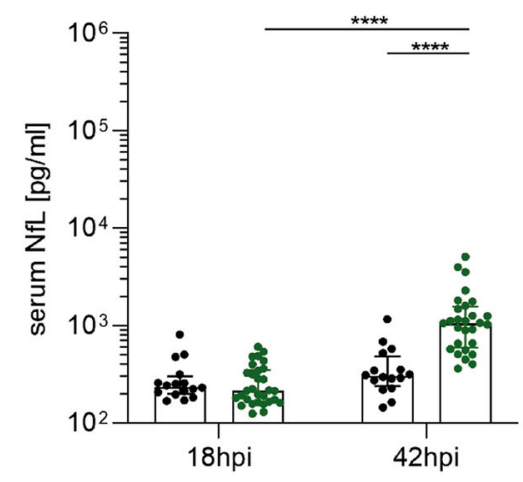

D

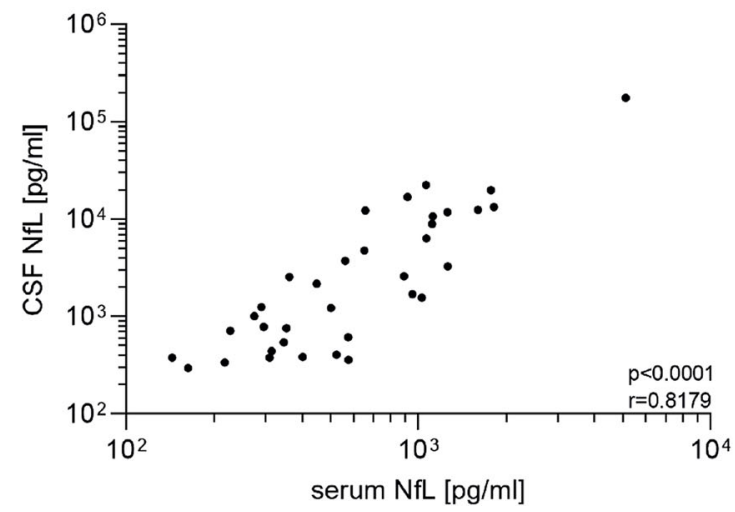

Fig. 2 The course of NfL in experimental PM. a, b At 18 hpi, infected animals displayed non-significantly increased CSF NfL levels ( $n=13$ ) compared to mock-infected animals $(n=6)$, whereas both displayed similar levels in serum NfL (mock-infected $n=16$; infected $n=30$ ). At 42 hpi, infected animals showed a significant increase of NfL levels in CSF $(n=22)$ and serum $(n=28)$ compared to mock-infected ones ( $p<0.0001)$ (CSF $n=13$; serum $n=16$ ). In mock-infected animals, both CSF and serum NfL levels remained stable between 18 and 42 hpi. NfL levels in CSF and serum showed a correlation at $18 \mathrm{hpi}(p<0.05, r=0.4716 ; n=18)(\mathbf{c})$ and at $42 \mathrm{hpi}(p<0.0001, r=0.8179 ; n=35)(\mathbf{d})$

animals at 18 hpi $(p<0.001)$ and 42 hpi $(p<0.0001)$ (Fig. 3d).

Cytokine levels correlated among each other at $18 \mathrm{hpi}$ (all $p<0.0001$; Suppl. Fig. 1). This was not the case for the correlation of cytokine levels with MMP-9, except for IL- $1 \beta$ at 18 hpi $(p=0.04, r=0.5126)$ and a trend at 42 hpi ( $p=0.07, r=0.3940)$ (Suppl. Fig. 2).

Table 1 shows the correlation of CSF cytokine and MMP-9 levels with NfL at different time points and for both fluid compartments. At $18 \mathrm{hpi}$, TNF- $\alpha$, IL-6, and IL- $1 \beta$ correlated with CSF NfL but not with serum NfL. In addition, cytokine levels at $18 \mathrm{hpi}$ correlated with both CSF and serum NfL at $42 \mathrm{hpi}$, with the exception of TNF- $\alpha$ that the set significance level for CSF NfL was missed by a margin. At $42 \mathrm{hpi}$, levels of IL- $1 \beta$ correlated with NfL in both fluid compartments. Moreover, MMP9 levels at 18 and 42 hpi were correlated with serum $\mathrm{NfL}$ at $42 \mathrm{hpi}$, while for CSF NfL this correlation became significant only at $42 \mathrm{hpi}$.

\section{Discussion}

Neurofilament light chain has been established in recent years as a neuron-specific marker of damage within the CNS, reflecting disease activity and therapy response in many neurological diseases $[23,28]$ and is now at the doorstep of clinical application [24]. However, little is known about whether NfL could be clinically useful in the same capacity in BM.

In the present study, we investigated the course of NfL release in ePM, a well-characterized model closely replicating the pathology of human PM. Here, neuronal damage is usually more severe and acute than in most other neurological diseases, but there is currently no biomarker established to specifically measure this injury directly. Increased concentrations of neuron-specific enolase (NSE) have been found in patients [29] and in animal models [30], but this marker is not specific for neuronal damage in CSF, as neuroendocrine tissues outside the CNS, most prominently in the lung, are important cellular sources. S100B is an astrocyte- 
A

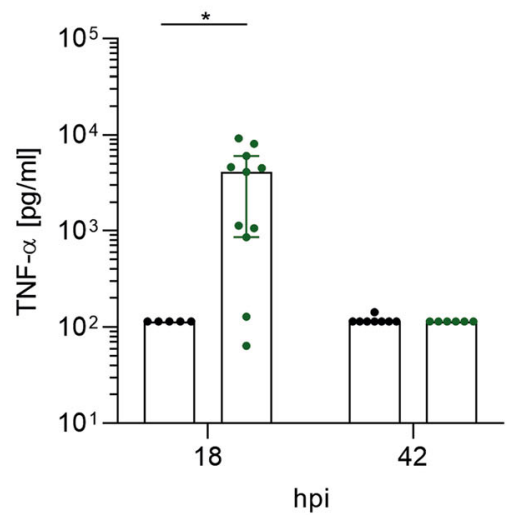

C

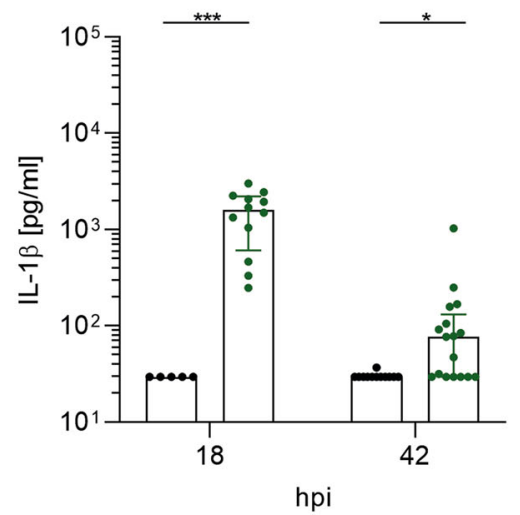

B

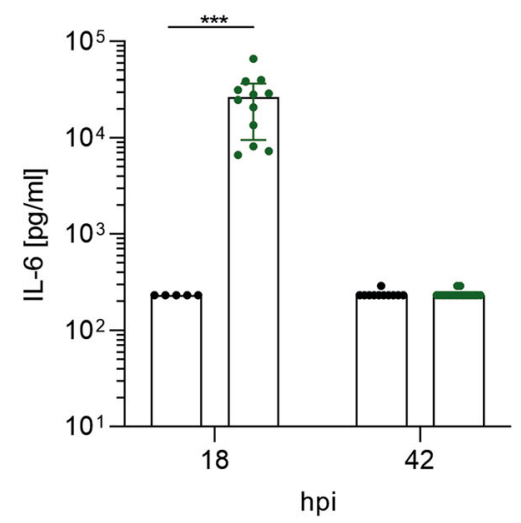

D

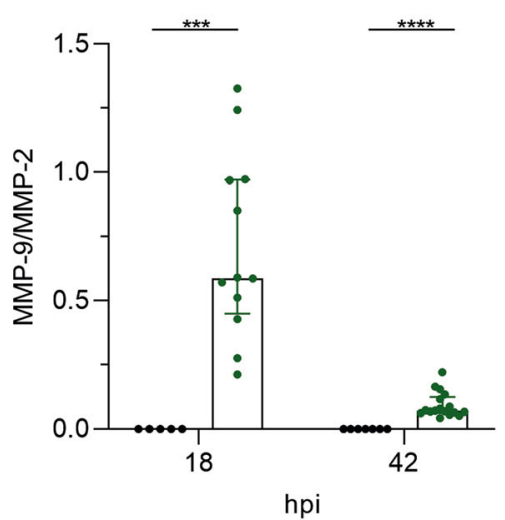

Fig. 3 Inflammatory CSF cytokines and MMP-9/MMP-2 levels during ePM. At 18 hpi before treatment with ceftriaxone, infected animals displayed significant higher TNF-a $(p=0.01)(n=11)(\mathbf{a}), \mathrm{IL}-6(p<0.001)(n=12)(\mathbf{b}), \mathrm{LL}-1 \beta(p<0.001)(n=12)(\mathbf{c})$, and MMP-9/MMP-2 $(p<0.001)(n=12)$ (d) levels compared to mock-infected animals ( $n=5$ for all cytokines and MMP9-/MMP-2). At 42 hpi, concentrations of TNF-a (a) and IL-6 (b) were similar in mock-infected $(n=8 ; n=11)$ and infected animals $(n=6 ; n=18)$ whereas IL-1 $\beta(p=0.02)(n=17)(\mathbf{c})$ and MMP-9/MMP-2 $(p<$ $0.0001)(n=17)(\mathbf{d})$ were still higher in infected compared to mock-infected ones $(n=12 ; n=7)$

derived marker of brain damage [31]. Several studies have reported an increase of S100B in CSF of human BM [32, 33 and in a rabbit model of PM [31]. However, S100B concentrations already peaked at $20 \mathrm{~h}$ after experimental infection and have a short serum half-life which may explain a high percentage of negative scores [34]. These factors may elucidate why both markers have not become standard tests in clinical settings, together with the fact that repetitive lumbar puncture to rely on CSF measurements is impracticable.

In contrast, the strong correlation of serum and CSF measures of NfL makes it an ideal marker to monitor CNS-based pathology. Present results demonstrate that $\mathrm{NfL}$ is upregulated in CSF and serum during ePM and confirm the close relationship between the two fluid compartments. Further, we showed that the increase of proinflammatory cytokines TNF- $\alpha$, IL- 6 , and IL- $1 \beta$ in CSF during an early stage of the disease correlated with the later degree of NfL release. Accordingly, CSF levels of MMP-9, an effector molecule of tissue damage that is released in the function of cytokine expression $[35,36]$, were also quantitatively linked to the amount of NfL release. The correlation of CSF cytokines and CSF cell counts has been described elsewhere $[37,38]$ while no correlation has been demonstrated between CSF cell counts and CSF NF in patients with BM [25].

Because our kinetic CSF study required cisterna magna punctures at two different time points in the same animal, we had to evaluate whether this procedure does lead to artifactual neuronal damage interfering with diseaserelated levels of NfL. The baseline intracisternal puncture with saline did not cause an increase in serum NfL concentration as compared to animals without any intervention. As our primary interest is to demonstrate the value of NfL as a serum-based marker for ePM and to limit the use of animals, we therefore refrained from performing referring CSF measurements.

At $42 \mathrm{hpi}$, mock-infected animals punctured for a second time at 18 hpi for CSF collection showed a small increase of CSF NfL concentrations compared to animals punctured only at baseline, while serum levels were unaffected. 
Table 1 Correlation of inflammatory cytokines, MMP-9, and NfL in CSF and serum. Green $=p<0.05$, yellow $=$ a trend towards $p<$ 0.05 , red $=$ non-significant

\begin{tabular}{|c|c|c|c|c|c|c|c|c|c|}
\hline \multirow{2}{*}{\multicolumn{2}{|c|}{$\begin{array}{l}\text { Correlation } \\
\text { [rho] }\end{array}$}} & \multicolumn{8}{|c|}{$\mathrm{CSF}$} \\
\hline & & \multicolumn{2}{|c|}{$\begin{array}{l}\text { TNF- } \alpha \\
{[\mathrm{pg} / \mathrm{ml}]}\end{array}$} & \multicolumn{2}{|c|}{$\begin{array}{c}\text { IL-6 } \\
{[\mathrm{pg} / \mathrm{ml}]}\end{array}$} & \multicolumn{2}{|c|}{$\begin{array}{c}\text { IL-1 } \beta \\
{[\mathrm{pg} / \mathrm{ml}]}\end{array}$} & \multicolumn{2}{|c|}{ MMP-9/MMP-2 } \\
\hline $\begin{array}{c}\mathrm{NfL} \\
{[\mathrm{pg} / \mathrm{ml}]} \\
\text { in }\end{array}$ & $\begin{array}{l}\text { Time } \\
\text { point } \\
{[\mathrm{hpi}]}\end{array}$ & 18 & 42 & 18 & 42 & 18 & 42 & 18 & 42 \\
\hline $\mathrm{CSF}$ & \multirow{2}{*}{18} & 0.6823 & & 0.7023 & & 0.7891 & & ns & \\
\hline serum & & ns & & ns & & ns & & ns & \\
\hline $\mathrm{CSF}$ & \multirow{2}{*}{42} & ns & ns & 0.8581 & ns & 0.9129 & 0.7075 & 0.8117 & 0.7342 \\
\hline serum & & 0.7915 & ns & 0.8474 & ns & 0.8249 & 0.6548 & 0.6316 & 0.6770 \\
\hline
\end{tabular}

We conclude that this intervention, likely in combination with a local inflammation due to the first puncture, caused a minor neuronal damage. Because the amount of artifactually induced NfL release was less than $2 \%$ of that found in ePM at $42 \mathrm{hpi}$, we conclude that the NfL levels measured are almost exclusively reflective of the infectionrelated pathology.

NfL can reach the systemic circulation by the bulk flow through the ventricular system and then exiting into the subarachnoid space where it is then reabsorbed into the blood stream [39]. In addition to this, current results suggest that in the initial phase of the disease, the BBB and blood-CSF barrier (BCSFB) are mainly intact, and only small amounts of NfL can reach the circulation. As a consequence of the BBB opening in the course of disease, the correlation of NfL in CSF and serum becomes stronger over time, and the correlation of serum levels with those of CSF cytokines seems to reflect the degree of neuroinflammation in blood circulation.

In ePM, TNF- $\alpha$, IL- 6 , and IL- $1 \beta$ appear early, prior to neutrophil recruitment, indicating that they are released by brain-resident cells $[40,41]$. TNF- $\alpha$ was shown to appear already $4 \mathrm{~h}$ after infection, reaching the peak at $12 \mathrm{~h}$ and persisting until $20 \mathrm{~h}$ after infection [26]. While the surge of cytokines released at this stage seems to directly lead to later neuronal damage, the induction of MMP-9 by these stimuli may be a further enhancing factor. MMP-9 induces degradation of the BBB and therefore facilitates leukocyte extravasation [12, 40]. Additionally, MMP-9 activates and regulates cytokine signaling in a positive feedback loop, enhancing the excessive inflammation $[42,43]$ and is suggested to play a role in glial and neuronal cell death [44] and development of neurological sequelae after PM [14].

During BM, microglia are activated by several stimuli including pathogen-associated and damage-associated molecular patterns (PAMPs \& DAMPs) and pro-inflammatory mediators, leading to the production of cytokines and chemokines. Nevertheless, excessive microglial activation can result in neuronal damage [45]. In the present study, we did not analyze the microglial status between 18 and $42 \mathrm{hpi}$. Previously, the microglia status was investigated at the morphological levels at 24 and $42 \mathrm{hpi}$, showing a transformation of thick ramified to amoeboid, phagocytic phenotype [46]. Since inflammation in the CSF is also resulting from the leucocytic infiltration, it is difficult to determine the 
specific involvement of microglia. At the transcriptomic level in the cortical tissue, a decrease of the component of the Toll-like receptor pathways between 24 and $72 \mathrm{hpi}$ was observed while there was an increase of the expression of genes guided by the clearance of tissue damage and regeneration [46].

This study has several limitations. We used an experimental model where bacteria are directly injected into the CSF which therefore does not reflect the natural course of the disease. Nonetheless, this method showed a higher success rate compared to methods of hematogenous infection, where successful meningitis is only developed in around $50 \%[47,48]$. In addition, it is a useful model for studying the interaction between the host and the pathogen as well as the complications resulting from the disease. Next, we only focused on the disease phase of PM up to $42 \mathrm{hpi}$, with inflammatory cytokine concentrations showing their peak between 18 and 24 hpi in infected animals and a resolution to almost background levels at 42 hpi $[27,49]$. The kinetic of NfL after $42 \mathrm{hpi}$ and during the recovery processes has not been determined yet. Further longitudinal investigations with later time points will be needed to assess the kinetic of NfL release and its correlation with chronic clinical sequelae of PM.

In the present study, the degree of cortical damage was limited and gross cortical necrosis was not observed (data not shown) and NfL release resulted mainly from brain-diffuse damage. The correlation of $\mathrm{NfL}$ release with defined morphological features of a neuronal damage is the next step underway in our laboratory.

Nevertheless, this study indicates that NfL is a very sensitive marker able to quantitate neuronal damage before it manifests with the most severe stage of typical PM pathology.

\section{Conclusion}

During the acute phase of BM, the upregulation of inflammatory mediators causes neuronal damage. Although inflammatory mediators could be used as predictors, they are not a direct indicator of neuronal injury. Furthermore, a clinically useful biomarker for BM needs to be blood-based to avoid the invasive procedure of lumbar puncture. Serum $\mathrm{NfL}$ is a sensitive biomarker which reflects neuronal damage with high specificity. Given the strong correlation between CSF and serum, current results provide the conceptual evidence for the use of NfL as a promising biomarker for the evaluation of neuroprotective agents in BM.

\section{Supplementary information}

Supplementary information accompanies this paper at https://doi.org/10. 1186/s12974-020-01966-3.

Additional file 1: Figure S1. At 18 hpi, inflammatory cytokines - TNF-a, $\mathrm{IL}-6$ and IL-1 $\beta$ - correlated with each other $(n=17)$.
Additional file 2: Figure S2. IL-1 $\beta$ significantly correlated with MMP-9 at $18 \mathrm{hpi}(\mathrm{p}=0.04, r=0.5126 ; n=17)(\mathbf{A})$, but showed only a trend at $42 \mathrm{hpi}$ $(p=0.07, r=0.3940 ; n=22)(B)$.

\section{Abbreviations}

BBB: Blood-brain barrier; BCSFB: Blood-CSF barrier; BHI: Brain heart infusion; BM: Bacterial meningitis; CFU: Colony-forming unit; CNS: Central nervous system; CSBA: Columbia sheep blood agar; CSF: Cerebrospinal fluid; DAMPs: Damage-associated molecular patterns; ePM: Experimental pneumococcal meningitis; hpi: Hours post-infection; MMP: Matrix metalloproteinase; NF: Neurofilament; NfL: Neurofilament light chain; NSE: Neuron-specific enolase; PAMPs: Pathogen-associated molecular patterns; PM: Pneumococcal meningitis; Simoa: Single molecule array

\section{Acknowledgements}

We thank Aleksandra Maceski, Franziska Simon, and Robert Lukesch for their excellent technical support and Pascal Benkert for the advice in statistics.

\section{Authors' contributions}

$\mathrm{NDL}, \mathrm{DG}$, and SLL conceived and designed the study. NDL performed the experiments. NDL, LM, DG, JK, DL, and SLL analyzed the data and contributed to the writing of the manuscript. The authors read and approved the final manuscript.

\section{Funding}

This work was supported by a grant from the Swiss National Science Foundation (Grant 310030_189136).

\section{Availability of data and materials}

The datasets used and/or analyzed during the current study are available from the corresponding author on reasonable request.

Ethics approval and consent to participate

All animal studies were approved by the Animal Care and Experimentation Committee of the Canton of Bern, Switzerland (license no. BE 01/18).

Consent for publication

Not applicable.

Competing interests

The authors declare that they have no competing interests.

\section{Author details}

${ }^{1}$ Neuroinfection Laboratory, Institute for Infectious Diseases, University of Bern, Friedbühlstrasse 51, 3001 Bern, Switzerland. ${ }^{2}$ Graduate School for Cellular and Biomedical Sciences (GCB), University of Bern, Bern, Switzerland. ${ }^{3}$ Neurologic Clinic and Policlinic, Departments of Medicine, Biomedicine and Clinical Research, University Hospital and University of Basel, Basel, Switzerland.

Received: 21 July 2020 Accepted: 24 September 2020

Published online: 07 October 2020

References

1. Mclntyre PB, O'Brien KL, Greenwood B, van de Beek D. Effect of vaccines on bacterial meningitis worldwide. Lancet. 2012;380:1703-11.

2. van de Beek D, Farrar JJ, de Gans J, Mai NT, Molyneux EM, Peltola H, Peto TE, Roine I, Scarborough M, Schultsz C, et al. Adjunctive dexamethasone in bacterial meningitis: a meta-analysis of individual patient data. Lancet Neurol. 2010;9:254-63.

3. Lucas MJ, Brouwer MC, van de Beek D. Neurological sequelae of bacterial meningitis. J Inf Secur. 2016;73:18-27.

4. Mook-Kanamori BB, Geldhoff M, van der Poll T, van de Beek D. Pathogenesis and pathophysiology of pneumococcal meningitis. Clin Microbiol Rev. 2011; 24:557-91.

5. Iliev Al, Stringaris AK, Nau R, Neumann H. Neuronal injury mediated via stimulation of microglial Toll-like receptor-9 (TLR9). FASEB J. 2004;18:412-4.

6. Leib SL, Kim YS, Chow LL, Sheldon RA, Tauber MG. Reactive oxygen intermediates contribute to necrotic and apoptotic neuronal injury in an infant rat model of bacterial meningitis due to group B streptococci. J Clin Invest. 1996;98:2632-9. 
7. Grandgirard D, Bifrare YD, Pleasure SJ, Kummer J, Leib SL, Tauber MG. Pneumococcal meningitis induces apoptosis in recently postmitotic immature neurons in the dentate gyrus of neonatal rats. Dev Neurosci. 2007;29:134-42.

8. Bifrare YD, Gianinazzi C, Imboden H, Leib SL, Tauber MG. Bacterial meningitis causes two distinct forms of cellular damage in the hippocampal dentate gyrus in infant rats. Hippocampus. 2003;13:481-8.

9. Hofer S, Grandgirard D, Burri D, Frohlich TK, Leib SL. Bacterial meningitis impairs hippocampal neurogenesis. J Neuropathol Exp Neurol. 2011;70:890-9.

10. Nau R, Gerber J, Bunkowski S, Bruck W. Axonal injury, a neglected cause of CNS damage in bacterial meningitis. Neurology. 2004;62:509-11.

11. Leib SL, Leppert D, Clements J, Tauber MG. Matrix metalloproteinases contribute to brain damage in experimental pneumococcal meningitis. Infect Immun. 2000;68:615-20.

12. Sellner J, Leib SL. In bacterial meningitis cortical brain damage is associated with changes in parenchymal MMP-9/TIMP-1 ratio and increased collagen type IV degradation. Neurobiol Dis. 2006;21:647-56.

13. Lakhan SE, Kirchgessner A, Tepper D, Leonard A. Matrix metalloproteinases and blood-brain barrier disruption in acute ischemic stroke. Front Neurol. 2013;4:32.

14. Leppert D, Leib SL, Grygar C, Miller KM, Schaad UB, Hollander GA. Matrix metalloproteinase (MMP)-8 and MMP-9 in cerebrospinal fluid during bacterial meningitis: association with blood-brain barrier damage and neurological sequelae. Clin Infect Dis. 2000;31:80-4.

15. Meli DN, Christen S, Leib SL. Matrix metalloproteinase-9 in pneumococcal meningitis: activation via an oxidative pathway. J Infect Dis. 2003;187:1411-5.

16. Yuan A, Rao MV. Veeranna, Nixon RA: Neurofilaments and neurofilament proteins in health and disease. Cold Spring Harb Perspect Biol. 2017;9.

17. Disanto G, Barro C, Benkert P, Naegelin Y, Schadelin S, Giardiello A, Zecca C, Blennow $K$, Zetterberg $H$, Leppert D, et al. Serum neurofilament light: a biomarker of neuronal damage in multiple sclerosis. Ann Neurol. 2017;81:857-70.

18. Lin YS, Lee WJ, Wang SJ, Fuh JL. Levels of plasma neurofilament light chain and cognitive function in patients with Alzheimer or Parkinson disease. Sci Rep. 2018;8:17368.

19. Soylu-Kucharz R, Sandelius A, Sjogren M, Blennow K, Wild EJ, Zetterberg H, Bjorkqvist M. Neurofilament light protein in CSF and blood is associated with neurodegeneration and disease severity in Huntington's disease R6/2 mice. Sci Rep. 2017;7:14114.

20. Lu CH, Macdonald-Wallis C, Gray E, Pearce N, Petzold A, Norgren N, Giovannoni G, Fratta P, Sidle K, Fish M, et al. Neurofilament light chain: a prognostic biomarker in amyotrophic lateral sclerosis. Neurology. 2015;84:2247-57.

21. Shahim P, Gren M, Liman V, Andreasson U, Norgren N, Tegner Y, Mattsson N, Andreasen N, Ost M, Zetterberg $\mathrm{H}$, et al. Serum neurofilament light protein predicts clinical outcome in traumatic brain injury. Sci Rep. 2016;6:36791.

22. Li J, Gu Y, An H, Zhou Z, Zheng D, Wang Z, Wen Z, Shen HY, Wang Q, Wang H. Cerebrospinal fluid light and heavy neurofilament level increased in anti-Nmethyl-d-aspartate receptor encephalitis. Brain Behav. 2019;9:e01354

23. Khalil M, Pirpamer L, Hofer E, Voortman MM, Barro C, Leppert D, Benkert $P$, Ropele S, Enzinger C, Fazekas F, et al. Serum neurofilament light levels in normal aging and their association with morphologic brain changes. Nat Commun. 2020;11:812.

24. Leppert D, Kuhle J: Blood neurofilament light chain at the doorstep of clinical application. vol. 6: Lippincott Williams and Wilkins; 2019.

25. Matsushige T, Ichiyama T, Kajimoto M, Okuda M, Fukunaga S, Furukawa S. Serial cerebrospinal fluid neurofilament concentrations in bacterial meningitis. J Neurol Sci. 2009:280:59-61.

26. Leib SL, Clements JM, Lindberg RL, Heimgartner C, Loeffler JM, Pfister LA, Tauber MG, Leppert D. Inhibition of matrix metalloproteinases and tumour necrosis factor alpha converting enzyme as adjuvant therapy in pneumococcal meningitis. Brain. 2001;124:1734-42.

27. Muri L, Le ND, Zemp J, Grandgirard D, Leib SL. Metformin mediates neuroprotection and attenuates hearing loss in experimental pneumococcal meningitis. J Neuroinflammation. 2019;16:156.

28. Khalil $M$, Teunissen $C E$, Otto M, Piehl F, Sormani MP, Gattringer T, Barro C, Kappos L, Comabella M, Fazekas F, et al. Neurofilaments as biomarkers in neurological disorders. Nat Rev Neurol. 2018;14:577-89.

29. Bartek J Jr, Thelin EP, Ghatan PH, Glimaker M, Bellander BM. Neuron-specific enolase is correlated to compromised cerebral metabolism in patients suffering from acute bacterial meningitis; an observational cohort study. PLoS One. 2016;11:e0152268.

30. Trostdorf F, Reinert RR, Schmidt H, Nichterlein T, Stuertz K, Schmitz-Salue M, Sadowski I, Bruck W, Nau R. Quinupristin/dalfopristin attenuates the inflammatory response and reduces the concentration of neuron-specific enolase in the cerebrospinal fluid of rabbits with experimental Streptococcus pneumoniae meningitis. J Antimicrob Chemother. 1999;43:87-94.

31. Schmidt H, Gerber J, Stuertz K, Djukic M, Bunkowski S, Fischer FR, Otto M, Nau R. S100B in the cerebrospinal fluid--a marker for glial damage in the rabbit model of pneumococcal meningitis. Neurosci Lett. 2010; 475:104-7.

32. Gazzolo D, Grutzfeld D, Michetti F, Toesca A, Lituania M, Bruschettini M, Dobrzanska A, Bruschettini P. Increased S100B in cerebrospinal fluid of infants with bacterial meningitis: relationship to brain damage and routine cerebrospinal fluid findings. Clin Chem. 2004:50:941-4.

33. Jung K, Goerdt C, Lange P, Blocher J, Djukic M, Gerber J, Spreer A, Nau R, Otto M, Schmidt H. The use of S100B and Tau protein concentrations in the cerebrospinal fluid for the differential diagnosis of bacterial meningitis: a retrospective analysis. Eur Neurol. 2011:66:128-32.

34. Unden J, Christensson B, Bellner J, Alling C, Romner B. Serum S100B levels in patients with cerebral and extracerebral infectious disease. Scand J Infect Dis. 2004;36:10-3.

35. Vecil GG, Larsen PH, Corley SM, Herx LM, Besson A, Goodyer CG, Yong WW. Interleukin-1 is a key regulator of matrix metalloproteinase-9 expression in human neurons in culture and following mouse brain trauma in vivo. J Neurosci Res. 2000:61:212-24

36. Reinhard SM, Razak K, Ethell IM. A delicate balance: role of MMP-9 in brain development and pathophysiology of neurodevelopmental disorders. Front Cell Neurosci. 2015;9:280

37. Srinivasan L, Kilpatrick L, Shah SS, Abbasi S, Harris MC. Cerebrospinal fluid cytokines in the diagnosis of bacterial meningitis in infants. Pediatr Res. 2016;80:566-72

38. Lepennetier G, Hracsko Z, Unger M, Van Griensven M, Grummel V, Krumbholz M, Berthele A, Hemmer B, Kowarik MC. Cytokine and immune cell profiling in the cerebrospinal fluid of patients with neuro-inflammatory diseases. J Neuroinflammation. 2019;16:219.

39. Simon MJ, lliff JJ. Regulation of cerebrospinal fluid (CSF) flow in neurodegenerative, neurovascular and neuroinflammatory disease. Biochim Biophys Acta. 1862;2016:442-51.

40. Muri L, Leppert D, Grandgirard D, Leib SL. MMPs and ADAMs in neurological infectious diseases and multiple sclerosis. Cell Mol Life Sci. 2019;76:3097-116.

41. van Furth AM, Roord JJ, van Furth R. Roles of proinflammatory and antiinflammatory cytokines in pathophysiology of bacterial meningitis and effect of adjunctive therapy. Infect Immun. 1996;64:4883-90.

42. Schonbeck U, Mach F, Libby P. Generation of biologically active IL-1 beta by matrix metalloproteinases: a novel caspase-1-independent pathway of IL-1 beta processing. J Immunol. 1998;161:3340-6.

43. Leppert D, Lindberg RL, Kappos L, Leib SL. Matrix metalloproteinases: multifunctional effectors of inflammation in multiple sclerosis and bacterial meningitis. Brain Res Brain Res Rev. 2001;36:249-57.

44. Anthony DC, Miller KM, Fearn S, Townsend MJ, Opdenakker G, Wells GM, Clements JM, Chandler S, Gearing AJ, Perry VH. Matrix metalloproteinase expression in an experimentally-induced DTH model of multiple sclerosis in the rat CNS. J Neuroimmunol. 1998;87:62-72.

45. Barichello T, Generoso JS, Simoes LR, Goularte JA, Petronilho F, Saigal P, Badawy M, Quevedo J. Role of microglial activation in the pathophysiology of bacterial meningitis. Mol Neurobiol. 2016;53:1770-81.

46. Wittwer M, Grandgirard D, Rohrbach J, Leib SL. Tracking the transcriptional host response from the acute to the regenerative phase of experimental pneumococcal meningitis. BMC Infect Dis. 2010;10:176.

47. Zwijnenburg PJ, van der Poll T, Florquin S, van Deventer SJ, Roord JJ, van Furth AM. Experimental pneumococcal meningitis in mice: a model of intranasal infection. J Infect Dis. 2001;183:1143-6.

48. Rodriguez AF, Kaplan SL, Hawkins EP, Mason EO Jr. Hematogenous pneumococcal meningitis in the infant rat: description of a model. J Infect Dis. 1991;164:1207-9.

49. Muri L, Grandgirard D, Buri M, Perny M, Leib SL. Combined effect of nonbacteriolytic antibiotic and inhibition of matrix metalloproteinases prevents brain injury and preserves learning, memory and hearing function in experimental paediatric pneumococcal meningitis. J Neuroinflammation. 2018;15:233.

\section{Publisher's Note}

Springer Nature remains neutral with regard to jurisdictional claims in published maps and institutional affiliations. 